\title{
A SEM-X-Ray assisted experimental approach for the determination of mechanical and thermal load - induced damage in MMCs
}

\author{
Victor N. Kytopoulos, Emilios Sideridis, John Venetis, Chrysoula Riga \\ Department of Mechanics, National Technical University of Athens, 5 Heroes of Polytechnion Avenue, Athens, Greece \\ victor@central.ntua.gr
}

Alexandros Altzoumailis

School of Chemical Engineering, National Technical University of Athens, 5 Heroes of Polytechnion Avenue, Athens, Greece ajumaily@central.ntua.gr

\begin{abstract}
An experimental technique is presented to evaluate mechanical and thermal load-induced microstructural damage, based on the Electron Probe Micro-Analysis (EPMA) principle, by which certain analytical potentialities of Scanning Electron Microscopy (SEM) are used. The aim of the study is to apply this technique in the case of metal matrix composites (MMCs). Based on earlier findings it is shown that by this technique the damage-controlled microstructural integrity distribution ahead of an edge-notch under tension is determined with sufficient reliability. To demonstrate this fact two MMCs were tested. Dog-bone specimens with an edge notch were subjected to slow tension up to their ultimate stress, the loading process was terminated and the EPMA technique was applied. The procedure was also applied after sudden cooling of the specimens by immersion in liquid hydrogen. It is shown that the MMC with larger differences between the elastic and plastic constants of the inclusion and the matrix exhibit increased proneness to mechanical and thermal load-induced damage. The findings obtained are discussed on the basis of the dominating combined influence of macro-microscopic mechanical and thermo-elastic stress concentration processes on the matrix-particle interfacial fracture strength.
\end{abstract}

KEYwORDS. (Micro)-damage; X rays; MMCs; Thermal shock-stress; Process zone; Microstructural integrity.

\section{OPEN ACCESS}

Citation: Kytopoulos, V.N., Sideridis, E. Venetis, J., Riga, Ch.., Altzoumailis, A., A SEMX-Ray assisted experimental approach for the determination of mechanical and thermal load - induced damage in metal matrix composites, Frattura ed Integrità Strutturale, 50 (2019) 414422.

Received: 24.01 .2019

Accepted: 28.05.2019

Published: 01.10.2019

Copyright: (C) 2019 This is an open access article under the terms of the CC-BY 4.0, which permits unrestricted use, distribution, and reproduction in any medium, provided the original author and source are credited.

\section{INTRODUCTION}

odern materials such as aluminum-alloy-based Metal Matrix Composites are the new candidates for a variety of engineering applications. Aluminum and its alloys have been used as the main constituent due to their wide application in advanced structural, automotive, aviation, aerospace, marine and defense sectors. The mechan- 
ical and tribological properties of the matrix material can be improved by adding various reinforcements ranging from very soft materials, like Graphite, to high hardened ceramic particulates like SiC. In recent years particulate reinforced aluminum-alloy composites have shown significant improvement in tribological properties, including sliding wear, abrasive wear, friction and seizure resistance [1-4]. A problem of major importance, especially in high temperature power and tribological technology, is to record and estimate the development of surface damage in severely mechanically and thermally loaded components made of these materials during service. For instance, in tribological applications [2, 4] due to high level of localization of the micro-cracks or crack-like micro effects mainly at the surface, the ability of a correct recording and estimation of surface damage becomes a challenging task. Such recording of damage would make it possible to retain the components in service until replacement is indicated by the damage level approaching a critical value. In this direction, various techniques, like for example sonic inspection, have a long tradition and constitute a strong base in engineering practice of damage control. However, very often micro-cracks and pores, which constitute basic material damage may not be detected or measured by sonic and other non-destructive techniques. In this context, it is noted that today there are several "common" macroscopic techniques for damage control and evaluation working on the macro-and meso-scale level $[5,6]$. At the same time, there also exist a lot of advanced physical techniques for surface microanalysis of solids [7-11]. However, very few references could be found in the literature concerning the application of the present SEM-EPMA technique to mechanical and thermal load-induced damage evaluation and characterization of materials [12-14].

In spite of this scarceness, it is to be accepted that convenient combination of this technique with other similar ones [13,1519], could provide valuable relationships between damage and other basic parameters of fracture mechanics such as Crack Opening Displacement (COD), the length of the damage zone etc. Therefore, it would be of importance to establish certain complementary experimental techniques for surface damage evaluation and characterization at microscopic level. Such a technique, called Scanning Electron Microscopy-aided Electron Probe Microanalysis (SEM-EPMA), was used for this purpose in the present study. Earlier attempts in this direction have shown that this technique can be a powerful tool providing valuable information about surface damage at microscopic level [12-14]. Therefore, in the present study a further attempt is made to apply an improved version of this technique for a deeper insight into the damage processes to be obtained. In particular, the proper application of this technique on a tensile loaded edge-cracked (notched) specimen was found to allow the evaluation, in a semi quantitative way, of the continuous distribution of mechanical and thermal load-induced micro-damage and hence the description of the microstructural integrity changes, ahead of the notch root.

\section{THEORETICAL CONSIDERATIONS}

\section{Basic damage aspects}

he material damage due to quasi-static increase of loading is brought about by the progressive nucleation and growth of microscopic cavities in the materials as a result of its elastic-plastic deformation, and is either elasticbrittle damage or elastic-plastic damage. The microscopic features of the nucleation and growth of such cavities vary significantly depending on the type of material, its macrostructure, the loading conditions, environmental and other factors. The elastic-plastic damage in composite materials is an extremely complicated process originating from the generation of various faults such as matrix cracking, interface degradation, delamination, fiber breakage, fiber-matrix debonding and other processes. This is in contrast to the damage development in geological materials [20] and structures made of geological materials [21] like and metals, where damage under a given loading scheme develops according to a single or a limited number of damage mechanisms. In general, it can be said that the process of gradual loss of integrity of a solid may be attributed to the increasing concentration of micro-cracks due to:

- The existence of initial cracks associated with the manufacturing process or the previous loading histories,

- Highly localized deformations and the attendant stress concentrations,

- Substantial differences in fracture toughness and elastic-plastic constants of the constituent phases, and

- Large fluctuations of the stresses which may be attributed to the inhomogeneity of the meso-scale structure.

\section{$X$-ray generation approaches}

The X-ray quanta are generated at different depths in the material and theoretically can be described by the so-called mass-depth distribution function $\varphi(\varrho q)$, where the depth is characterized by the effective variable, $\varrho z$, in units of $\mathrm{mg} / \mathrm{cm}^{2}$. $\mathrm{X}$-rays generated at a depth $\mathrm{z}$ and collected at a given take-off angle are absorbed along the path length up to the surface layer [22-23]. The absorption process is characterized by an exponential decrease of the function of the linear-absorption (attenuation) coefficient $\mu$, of the material and, is the average of these coefficients for all the elements of the material. In a 
simple, first-order approximation model the distribution function $\varphi(\varrho z)$ of X-rays generation can be described by a single exponential decrease [23]:

$$
\varphi(\rho z)=\sigma e^{-\sigma \rho z}
$$

where $\sigma$ is a material-instrument set-up constant and $\varrho$ the mass density of material. At the same time the attenuation (absorption) processes is given by Beer's law as $\exp [-\mu \mathrm{z}]$, where $\mathrm{z}$ is the X-Ray travelling depth. Thereafter the emitted and detected X-ray intensity can be described, at first, as:

$$
I_{e n n}=\int_{0}^{z_{x}} e^{-\sigma e z} e^{-\mu z} d z
$$

where the mass density $\varrho$ is assumed in a first approximation to remain constant along the X-ray generation path $\%$ Nevertheless, the presence of crack-like micro-defects, i.e., volumetric damage in the material, imposes a related local variation of the mass density $\varrho$. As such, the above integration should be made with respect to the "effective" variable, $\varrho \%$ called mass-depth. Therefore the above integral takes the final form:

$$
I_{e m}=K_{\sigma} \int_{0}^{\rho Z_{x}} e^{-\sigma \rho z} e^{-\bar{\mu} \gamma \rho} d(\rho z)
$$

where $\bar{\mu}=\mu / \rho$ is the so-called mass absorption (attenuation) coefficient, which is a very important material constant for the non-destructive testing given that it is independent of the physical and/or chemical state of the material [22-24]. The constant $K_{\sigma}$ takes into account the atomic mass and number as well as fluorescence effects [23] while $Z_{\mathrm{x}}$ is the maximum effective depth of X-rays generation. Integration with respect to $\left(\varrho_{z}\right)$ yields:

$$
I_{e m}=\frac{K_{\sigma}}{\bar{\mu}+\sigma}\left[1-e^{-(\bar{\mu}+\sigma) \rho Z_{x}}\right]
$$

Furthermore, it is valid that maximum mass-depth $\varrho_{\mathrm{x}}$ is almost constant under the same experimental set-up conditions [23]. On the basis of this fact, one may similarly assume that the effective mass-volume $\mathrm{M}_{\mathrm{x}}$ of $\mathrm{X}$-rays generation, sampled by the electron beam, remains almost constant. Hence, one may write:

$$
M_{x}=\rho V_{x} \approx \rho z_{x}^{3}=\text { const }
$$

where $\mathrm{V}_{\mathrm{x}} \approx Z_{\mathrm{x}}{ }^{3}$ is the associated effective maximum volume of $\mathrm{X}$-rays generation. Using now Eq.(3a) and substituting $q_{x}=\left(\right.$ const $\left./ \varrho^{1 / 3}\right)$ into Eq. (3) one arrives at the final-general form of emitted $x$-Ray signal intensity:

$$
I_{e m}=A\left[1-e^{\left(-a \rho^{2 / 3}\right)}\right]
$$

Constants A, $\alpha$ take into account all constants of Eq.(3). As such, the basic Eq.(4) implies that the emitted and detected signal intensity should increase (decrease) monotonically with increasing (decreasing) local mass density @. Since damage can be assumed to be (in a first approximation) inversely proportional to the local mass density it means that the measured damage degree should monotonically increase (decrease) with decreasing (increasing) signal emission intensity, given by Eq.(4).

\section{EXPERIMENTAL DETAILS}

\section{Methods}

he X-rays used are generated and emitted from a specimen bombarded with a focused electron beam of the Scanning Electron Microscope. The X-ray generation and emission is a result of complex electron beam-specimen interactions, which describe the mechanisms for both characteristic and continuum X-ray production. In this study 
both of these X-ray productions were taken into consideration, which means that the X-ray signal intensity used consists of the overlapping of characteristic and continuum X-ray of the material. In this way the applied manner of measurements exhibits a great advantage over the usually applied elemental X-ray microanalysis technique where the imposed measuring conditions and the precautions including atomic number, absorption and fluorescence factors (ZAF) are much more stringent [22]. In this study, the X-ray detection was made by using a Microspec 201-type wavelength dispersive spectrometer with special analyzing crystals. This spectrometer was attached to a Cambridge-S4-10-type, SEM, installed in the Laboratory of Strength and Materials of the National Technical University of Athens.

The edge-notched specimens, of dog-bone geometry, were loaded in tension using a specially designed servo-motor device and examined in-situ in the SEM-EPMA system. Fig.1 shows the geometry of the sampled region by SEM-electron beam ahead of the notch root of the specimen. The electronic scan frame and line set-up on the SEM were adequately selected to allow convenient measurements imposed by the conditions of X-ray signal collection. For instance, since electronic deflection of the beam can lead to defocusing of the X-ray spectrometer the desired line scans were performed by stepping the sample under a static electron beam.

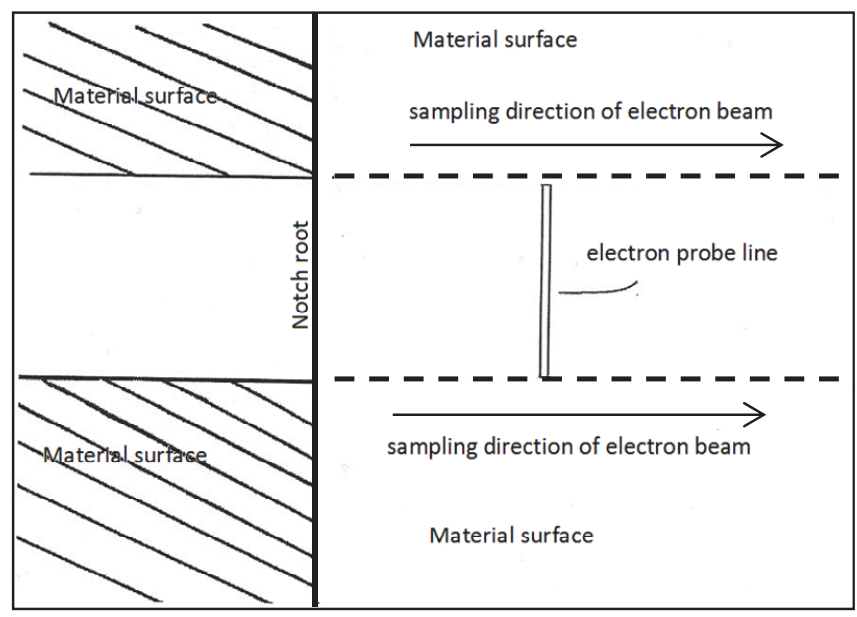

Figure 1: Electron beam of scanning - stepping set up principle.

The stepping procedure was made by means of a high-precision micro-positioning system of the loading stage. In this context, it is noted that the emitted X-ray beam intensity is strongly depended on the electron beam intensity and because of this the measurements were performed for fixed electron intensity. This was made by monitoring the electron beam by means of a special specimen current apparatus of high sensitivity $\pm 10^{-12}$ Amp attached to the SEM. Furthermore, because of the statistical nature of the X-ray emission phenomenon the counting error is independent of counting time, it is beneficed to record a pre-determined fixed number of counts rather than to operate for a fixed time period [10]. In this sense the measured X-rays emission intensity should be appropriately scaled with the corresponding time signal variation. For this reason the measurements were carried out by introducing a time-converted signal given as:

$$
\begin{aligned}
& t_{i} I_{e m i}=I_{o}=\text { constant } \\
& \tilde{I}=\frac{1}{t_{i}}
\end{aligned}
$$

where $I_{0}$ is the predetermined fixed number of counts, $I_{e m} i$ is the emission intensity from the "i" point on the surface of the specimen and $t_{i}$ is the corresponding measured specific accumulation time. Thus, the main measurement parameter in Eq. (5b), $I$, is the so-called specific accumulation rate. Taking into account, the discussion concerning Eq.(4), one can generally state that the specific parameter $\tilde{I}$, may reflect a measure of the damage-controlled microstructural integrity change in the material. The data presented are the result of the average of measurements taken from three specimens.

\section{Materials}

In this study, two MMCs were tested, namely the $8090-\mathrm{Al}-\mathrm{Li}$ and $2124-\mathrm{Al}-\mathrm{Cu}$. Both were fabricated by liquid metallurgy. This method is the most economical to fabricate composite materials. The mixed molten metal at $710{ }^{\circ} \mathrm{C}$ was poured into 
the pre-heated iron molds. The matrix was reinforced with $20 \%$ volume fraction SiC particles of radius about $3 \mu \mathrm{m}$. The composites were prepared by BP-International by mixing and blending of $\mathrm{Al}$ matrix alloy and $\mathrm{SiC}$ powders followed by canning, vacuum de-gassing and consolidation and then hot rolling to plate and sheet.

The basic mechanical properties of these two materials are given in Table 1. The specimens were dogbane-shaped in accordance with the requirements of the grips of the loading device (of load capacity equal to $2.5 \mathrm{kN}$ ) specially designed for in-situ observations by SEM. The edge- notch was machined very carefully by means of a rotating diamond disc-slow cutting apparatus (in order to avoid any parasitic damage).

\begin{tabular}{ccccccc}
\hline Type of MMC-material & \multicolumn{3}{c}{ AL-Li 8090} & \multicolumn{3}{c}{ Al-Cu 2124 } \\
Constituents & Alloy & MMC & Change (\%) & Alloy & MMC & Change (\%) \\
Elastic Modulus (GPa) & 92.5 & 114.0 & 23 & 80.0 & 109.9 & 37 \\
Tensile Strength (MPa) & 428 & 575 & 34 & 435 & 622 & 43 \\
Ductility (\%) & 4.5 & 4.0 & -11 & 6.7 & 4.9 & -27 \\
\hline
\end{tabular}

Table 1: Mechanical properties of the materials tested.

\section{RESULTS AND DISCUSSION}

I n Figs.2(a,b) the data obtained from the measurements of micro-damage controlled micro-structural integrity distribution ahead of the notch root for a 2124 MMC- and a 8090 MMC-specimen, respectively are presented. Taking into consideration the discussion concerning Eqs.(5), one can clearly observe that this distribution, measured by the specific-count accumulation rate $\tilde{I}$ shows a distinct decrease towards notch root. Also this signal tends to equilibrate at certain distance $\varrho_{z}$ away of notch root. At this distance the damage has a vanishing limit value. The parameter $\varrho_{z}$, called fracture process zone, is an important factor in the experimental fracture mechanics of materials $[7,19,25]$. The fracture process or cohesive zone is a small characteristic region surrounding the crack tip or notch where micro-fracture develops mainly through the successive stages of inhomogeneous void growth and coalescence and bound breaking on atomic scale. In this context, the increased size, of about 5 times, of the process zone of the $8090 \mathrm{MMC}$, compared to the 2124 MMC specimen is to be properly highlighted.

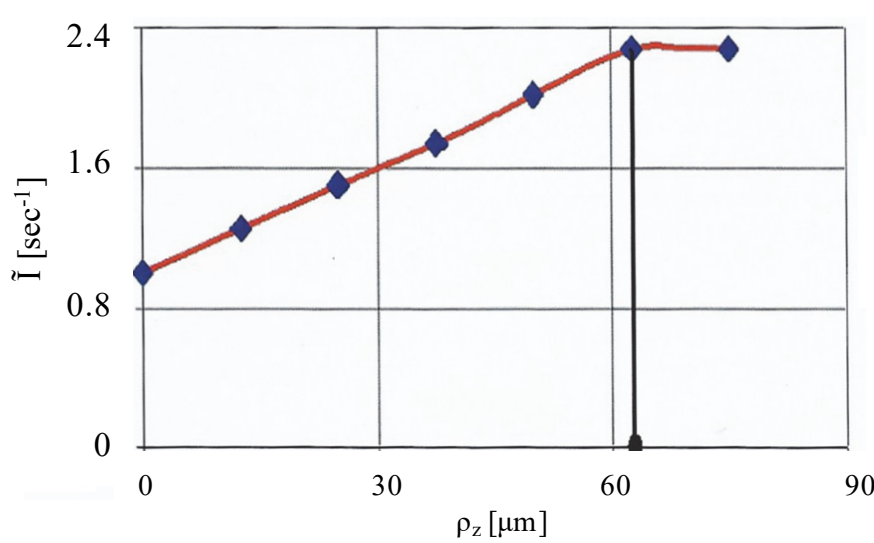

(a)

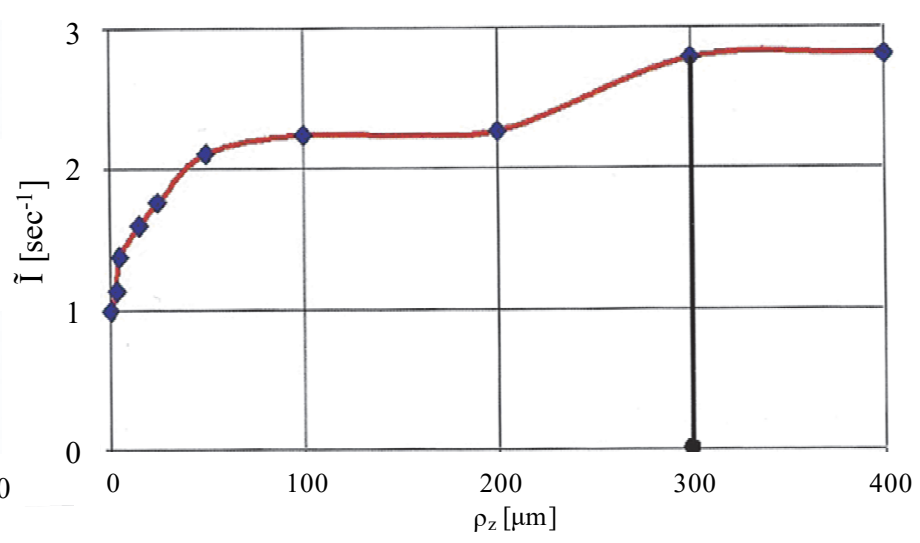

(b)

Figure 2: Reduced structural integrity change distribution ahead of notch root for material (a) 2124 MMC and (b) 8090 MMC. Note that the strain rate for both cases was equal to $10^{-5} \mathrm{sec}^{-1}$.

As shown in Fig. 3 the proposed damage degree number $q_{d}=A_{d} / A_{0}$ was determined, where $A_{0}$ is the total sampled area and $A_{d}$ is the damage-controlled integrity loss area. In Table 2 one can see the larger damage degree number obtained for the $2124 \mathrm{MMC}$ material compared to the $8090 \mathrm{MMC}$, for the same strain rate conditions (of $10^{-5} / \mathrm{s}$ ). Comparing now the two parameters $\varrho_{z}$ and $q_{d}$ of these materials one can deduce that a larger damage degree or integrity loss is developed in 2124 MMC "along" a smaller fracture process zone. 


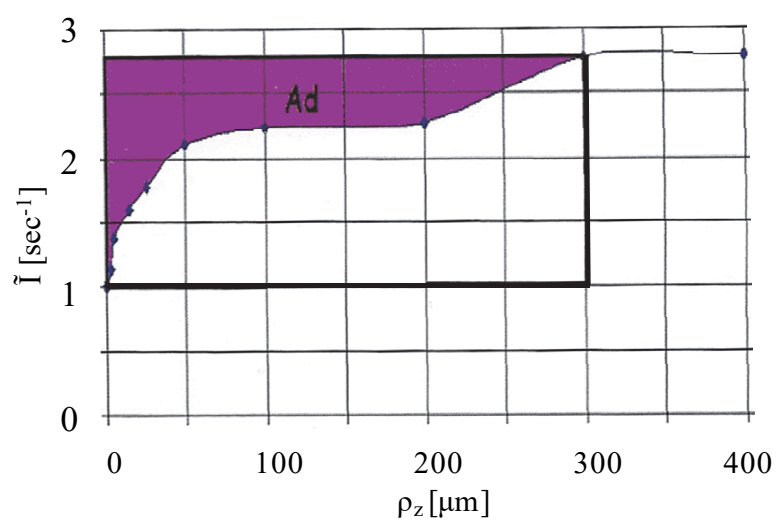

Figure 3: Integral area principle for calculation of damage or integrity loss number $\mathrm{q}_{\mathrm{d}}$.

To further enlighten this fact a new parameter, the specific damage number $\delta=\mathrm{qd}_{\mathrm{d}} / \varrho_{\mathrm{z}}$, is introduced, describing the intensity of damaging processes. Thereafter it seems that the $2124 \mathrm{MMC}$ with higher matrix ductility (Table 1), responds to loading with a larger specific damage number than the $8090 \mathrm{MMC}$, which has lower matrix ductility. A reasonable explanation for this interesting behavior could be given as follows: The more ductile metal matrix is associated with a higher strain hardening rate-induced dislocation motion activity [26]. This means that in this matrix (compared to less ductile ones) larger dislocation piling-up accumulations at metal matrix-SiC particle interface sites may occur at early stages of loading. The high level of dislocation accumulation, in turn, produces strong stress concentration fields at these sites, promoting premature and intensive interfacial degradation activity, reflected by rapid lowering of the interfacial strength [27]. This implies, in turn, strong matrix-particle debonding-decohesion and micro-voids formation effects, which on further loading induce linkage of debonded particles followed by rapid crack initiation and propagation and final fracture. In this case, the related elastic-plastic damage processes are associated with energy absorption, by which a significant portion of the total micro-fracture energy flows into the crack-tip region dissipated within a "restricted" and characteristic damage process zone-volume, screened from the outer undamaged region, leading to intensive micro-failure events reflected by a large specific damage number. In Figs.4(a,b) the damage controlled integrity change distribution ahead of notch root in $2124 \mathrm{MMC}$ and in $8090 \mathrm{MMC}$, respectively for a higher strain rate is presented. One can observe the dramatic reduction of the fracture process zone compared to the lower stain rate (see Figs.2(a,b)). In this context, in Table 2 one can observe the increased specific damage number for both MMC materials with increasing strain rate of deformation. From the above findings the obvious embrittling influence of strain rate on the damage process can be deduced. This may be due to the dominating quasi-adiabatic process where high deformation rates limit the dissipation time required for the absorbed micro-failure energy to form new surfaces. Hence the corresponding effective-specific damage process volume is reduced, a fact that is experimentally observed by the reduction of the measured process zone length $\varrho_{z}$. Moreover the high deformation rate seems to exhibit a lower embrittling influence on $8090 \mathrm{MMC}$. This is reasonable, since at high deformation rates the dislocation motion activity in the less ductile matrix (compared to the more ductile one) is subjected to a larger fractional reduction, a fact that (as was explained earlier) should induce corresponding micro-damage activity with reduced intensity.

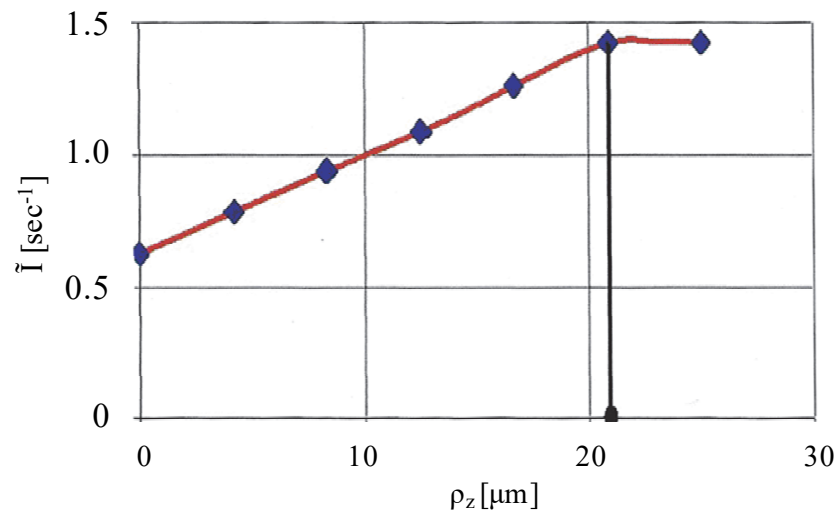

(a)

Figure 4: Reduced structural integrity change distribution ahead of notch root for material (a) 2124 MMC and (b) 8090 MMC. Note that the strain rate for both cases was equal to $10^{-2} \mathrm{sec}^{-1}$.

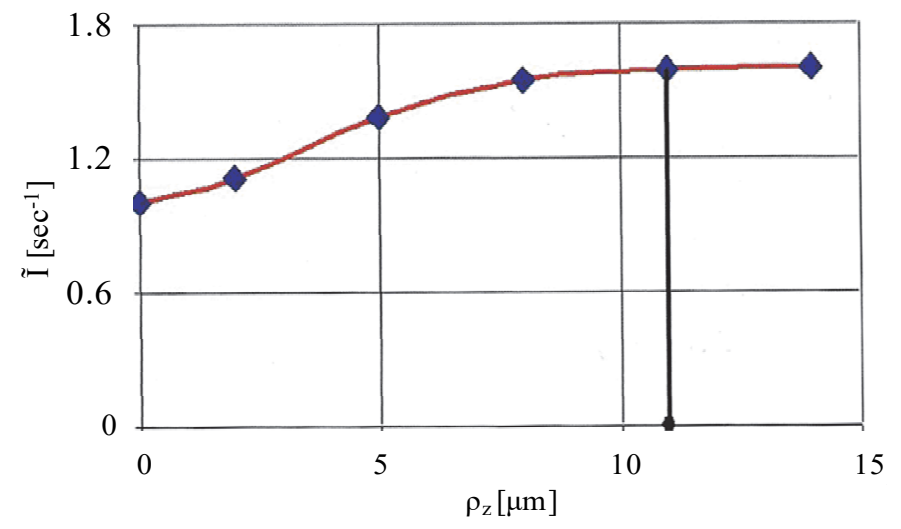

(b) 


\begin{tabular}{ccc}
\hline Material and strain rate & $\begin{array}{c}\text { Damage number } \\
\mathrm{q}_{\mathrm{d}}=\mathrm{A}_{\mathrm{d}} / \mathrm{A}_{0}\end{array}$ & $\begin{array}{c}\text { Specific damage number } \\
\delta=\mathrm{q}_{\mathrm{d}} / \varrho_{\mathrm{z}}\end{array}$ \\
MMC 8090 (Strain rate $\left.10^{-5} / \mathrm{sec}\right)$ & 0.27 & $9 \times 10^{-4}$ \\
MMC 8090 (Strain rate $\left.10^{-2} / \mathrm{sec}\right)$ & 0.37 & $3.1 \times 10^{-2}$ \\
MMC 2124 (Strain rate $\left.10^{-2} / \mathrm{sec}\right)$ & 0.58 & $3.8 \times 10^{-2}$ \\
MMC 2124 (Strain rate $\left.10^{-5} / \mathrm{sec}\right)$ & 0.33 & $5.5 \times 10^{-3}$ \\
\hline
\end{tabular}

Table 2: Basic, final results of micro-damage evaluation measurements of the investigated materials, before thermal shock.

Furthermore, in an isotropic body subjected to a non-uniform temperature distribution, the elements attempt to undergo dilation (or shrinkage) as a result of the temperature changes from an initially uniform temperature. However, the elements cannot dilate (or shrink) in an unrestricted manner. Since the body must remain continuous during the temperature change there will be partial constraint internally, even if the body externally is unconstrained, as to change in geometry. One can then introduce in this way a general stress field in the body, with a parameter called thermal stress [28]. Highspeed aircraft and space vehicles are subjected to considerable thermal stress from aerodynamic or solar heating on the outside surfaces and from the heat originating in propulsion system. Furthermore, even without external constraint, thermal shock can occur due to the steep temperature gradients created because of a finite thermal conductivity. Again, such a thermal shock is the stress state resultant of combined thermal conductivity and steep temperature gradient effect. For example, rapid cooling of the surface of a high-temperature wall is accompanied by surface tensile stresses. The surface contracts more than the interior, which is still relatively hot. As a result, the surface "pulls" the interior, into compression and "pulls" itself into tension. With the inevitable presence of Griffith flaws at the surface, this surface tensile stress creates the clear potential for brittle fracture. The ability of a material to withstand a given temperature change depends on a complex combination of thermal expansion, thermal conductivity, overall geometry, and the inherent brittleness of the material. The presence of Griffith flaws in solids in form of cracks or crack-like defects are usually classified as microscopic, meso-scopic and macroscopic according to crack length [5].

Microscopic cracks in the sub-micrometer range often exist as a result of the material production processes. On thermal loading of materials, surface cracks propagate and additional cracks can be generated, which may finally lead to fracture. In other words, with thermal shock, stresses are caused by heterogeneous thermal expansion of the loaded material, which may be a result of both a heterogeneous material structure and a heterogeneous (local) energy load. Moreover, the above described thermal cracking damage, is very critical in many primary and secondary manufacturing processes of materials such as casting, forging and welding where due to the improper related parameter such a damage can develop [29].

In Fig. 5 the measured X-Ray intensity before tensile loading ahead of edge notch for the heat treated specimens by sudden cooling in liquid hydrogen at $-196^{\circ} \mathrm{C}$ temperature is presented. Thus sudden cooling in this case produces the socalled thermal shock by which, due to high thermal stresses, the fracture of material may occur. The produced thermal stresses are proportional to $\Delta \alpha \Delta \mathrm{T}$ where $\Delta \mathrm{T}$ is the temperature difference between cooling agent $\left(-196^{\circ} \mathrm{C}\right)$ and specimen $\left(20{ }^{\circ} \mathrm{C}\right)$ and $\Delta \alpha$ the thermal expansion coefficient of the MMC material. In this case two dominant parallel processes may occur: a fracture mechanics - controlled macroscopic thermo-elastic stress concentrations around a cut [30] and a damage mechanics - controlled microscopic one around inclusions ( $\mathrm{SiC}$ particle) [5] .The microscopic process is characterized by highly localized thermal shock stresses produced between $\mathrm{SiC}$ particle and matrix where due to large differences between thermal expansion coefficients, $\Delta \alpha$, of particle and matrix these stresses may lead to intensive and rapid mechanical degradation of interphase microstructure. The combined effect of these two thermal stress concentration processes result in the interfacial damage - controlled structural integrity change shown in Fig.5.

One can see in this figure that MMC-2124 material shows a distinct higher thermal damage response than the other one. Thus, one can argue that the composite material with large differences between the components ( $\mathrm{SiC}$ and matrix) concerning the tensile moduli and ductility, are more prone to thermal shock damage. In Fig.6 the increased damage response is presented for the same specimens as in Fig. 5 after tensile loading to ultimate stress. This was expected since damage accumulated by thermal shock, on tensile loading, acts as an initial - present damage in the material. The basic data for the specimens after thermal shock treating are given in Table 3. One can deduce that the initial presence of damage in the material, after thermal shock, exhibits a considerable influence on the subsequently tensile load - induced damage. In this aspect one can at first observe the increased proneness to thermal shock of the MMC2124 material compared to the other one. Moreover, the combined effect of tensile load and thermal shock induced damage is larger for the MMC2124 material. This can be seen first by the large shift of both curves to lower values of measured count accumulation intensity and 


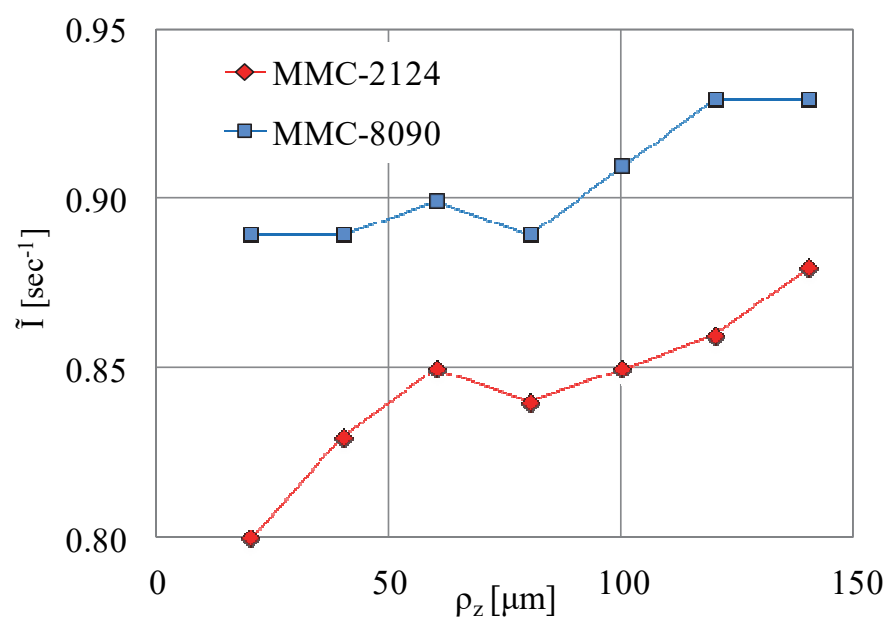

(a)

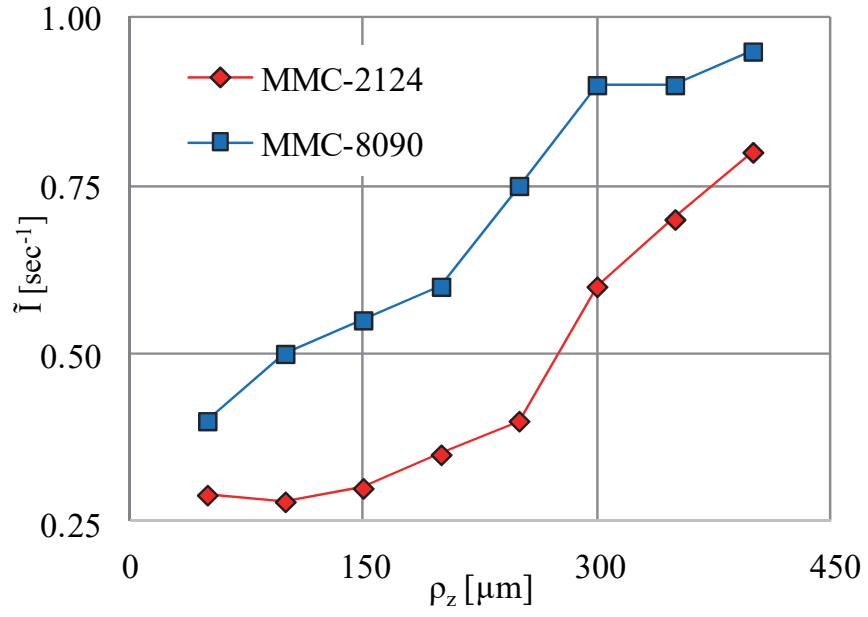

(b)

Figure 5: Reduced structural integrity changes ahead of notch root after thermal shock process (a) before tensile loading and (b) after subsequent tensile loading. Reduction to unity of undamaged (virgin) material. Strain rate $10^{-5} \mathrm{sec}^{-1}$.

$\begin{array}{ccc}\text { MATERIAL } & \begin{array}{c}\text { Damage number } \\ \mathrm{q}_{\mathrm{d}}\end{array} & \begin{array}{c}\text { Specific damage number } \\ \delta=\mathrm{q}_{\mathrm{d}} / \varrho_{\mathrm{z}}\end{array} \\ \text { MMC } 8090 \text { thermal shock } & 0.13 & 3.0 \times 10^{-4} \\ \text { MMC 2124 thermal shock } & 0.19 & 2.3 \times 10^{-2} \\ \text { MMC 8090 thermal shock and tensile load } & 0.33 & 1.3 \times 10^{-2} \\ \text { MMC 2124 thermal shock and tensile load } & 0.57 & 2.7 \times 10^{-3}\end{array}$

Table 3: Basic final results of micro-damage evaluation measurements of the investigated materials, after thermal shock.

second by the formation of an increased process zone ahead of the notch root. Thereafter, by comparing the data presented in Tables 2 and 3, one can generally state that the combined (superimposed) mechanical and thermal damage processes seems to influence more the MMC 2124 and less the MMC 8090 material.

\section{Conclusions}

The experiments conducted showed that, within the experimental scatter of the proposed semi-quantitative approach and under the same experimental conditions, the MMC with higher ductility of the matrix exhibits a higher proneness to mechanical load - induced damage compared to the MMC material with lower ductility. Based on the principle of elasticplastic damage, this behavior can be explained by the general fact that larger differences in ductility between matrix and SiC particles may result to a larger misfit and accommodation loss between inclusion and matrix. This, in turn, leads to an associated intensive micro-cracking and debonding damage activity, taking place within the matrix-particle interface of the composite. In this aspect strain hardening rate effects seem to play a decisive role.

Furthermore, it was shown that increasing deformation rate leads to significant changes of the damage activity ahead of the edge-crack, a fact that is equivalent to a strain rate induced embrittlement of the material. This behavior seems to be more pronounced in MMCs with higher matrix ductility.

At the same time, it is concluded that the material with larger differences in the elastic-plastic parameter of its constituent phases seems to exhibit a larger proneness to thermal shock damage. In general, the observed proneness to thermal shock damage may be explained by the combined effect of macroscopic and microscopic thermo-elastic stress concentration processes which may promote at first the physico-mechanical degradation of the particle-matrix interphase.

In general, it can be stated that the proposed technique can give a reliable semi-quantitative approach for micro-damagecontrolled structural integrity evaluation and characterization of materials. 


\section{REFERENCES}

[1] Stachowiak, G. and Batchelor, A.W. (2013). Engineering Tribology, $3^{\text {rd }}$ edition, Oxford, UK, Elsevier-ButterworthHeinemann

[2] Stachowiak, G. (Ed) )2005). Wear-Materials, Mechanisms and Practice. John Willy \& Sons Ltd, England

[3] Shizhu Wen, Ping Huang (2018). Principles of Tribology, $2^{\text {nd }}$ edition John Wiley \& Sons, Singapore

[4] Hutchings, I., Shipway, P. (2017). Tribology-Friction and wear of Engineering Materials, $2^{\text {nd }}$ edition. Elsevier, Butterworth-Heinemann, United States

[5] Krajcinovic, D. (1985). Continuous damage mechanics revisited: Basic concepts and definitions, Journal of Applied Mechanics, 52, pp. 829-834

[6] Yang, Q., Chen, X., Zhou, W. (2005). On microscopic thermodynamic mechanisms of damage evolution laws, International Journal of Damage Mechanics, 14, pp. 261-293

[7] Kytopoulos, V.N. (1991). Contribution of SEM-technique to investigation of elastic-plastic micro-failure processes in materials, $\mathrm{PhD}$ Thesis, Laboratory of strength of materials, National Technical University of Athens, Greece

[8] Vickerman, J., Gilmore, I. (2009). Surface Analysis - The Principal Techniques, John Wiley \& Sons

[9] Yacobi, B.G. and Holt, D.B. (1994). An Introduction to Microanalysis of Solids. In: Yacobi B.G., Holt D.B., Kazmerski L.L. (eds.) Microanalysis of Solids. Springer, Boston, MA.

[10] Flewitt, P.E. and Wild, R.K. (1994). Physical Methods for Materials Characterization, Institute of Physics Publishing, Bristol and Philadelphia

[11] Wetzig, K. and Schulze, D. (eds.) (1995). In situ Scanning Electron Microscopy in mAterials Reseaech, Akademie Verlag, Berlin.

[12] Papadopoulos, G. and Kytopoulos, V.N. (2001). Micro-failure behavior of $\mathrm{Al}_{2} \mathrm{O}_{3}$-Ceramics studied by X-ray EPMA. ICCE/8, Annual International Conference, Spain, 5-11/8/2001, pp. 715-716

[13] Riga, Ch. (2007). MSc-Thesis, School of Applied Mathematics and Physics, Section of Mechanics, National Technical University of Athens, Greece

[14] Kytopoulos, V.N., Riga, Ch. and Kourkoulis, S.K. (2007). Notch Root Opening Displacement versus Damage for Particulate MMC. In: Gdoutos E.E. (ed.) Experimental Analysis of Nano and Engineering Materials and Structures, Springer, Dordrecht, pp. 133-135

[15] Andrianopoulos, N.P., Kourkoulis and S.K., Saragas, S. (1997). COD measurements and optimum exploitation of metal matrix composites for aerospace applications, Engineering Fracture Mechanics, 57, pp. 565-576

[16] Kourkoulis, S.K. and Andrianopoulos, N.P. (2000). Plastically induced anisotropy on metal matrix composites, Mechanics of Composites Materials and Structures, 7(1), pp. 1-18

[17] Kourkoulis, S.K. (2001). The influence of cracks on the mechanical behavior of particulate MMCs: An experimental study, Archives of Mechanics, 53(4-5), pp. 439-456

[18] Kourkoulis, S.K. (2002). Quantifying the plastic anisotropy for particulate metal matrix composites, Advanced Composites Letters, 11(4), pp. 153-163

[19] Kourkoulis, S.K. (2003). The process zone around the tip of cracks in metal matrix composites. Archives of Mechanics, 55(5-6), 407-430

[20] Kourkoulis, S.K., Prassianakis, I., Agioutantis, Z. and Exadaktylos, G.E. (2006). Reliability assessment of the NDT results for the internal damage of marble specimens, International Journal of Material and Product Technology, 26 (1/2), pp. $35-56$

[21] Kourkoulis, S.K., Ganniari-Papageorgiou, E. and Mentzini, M. (2010). Dionysos marble beams under bending: A contribution towards understanding the fracture of the Parthenon architraves, Engineering Geology, 115(3-4), pp. 246-256

[22] Goldstein, J.I. (1992). Scanning Electron Microscopy and X-Ray Microanalysis: A Text for Biologists, Material Scientists and Geologists, $2^{\text {nd }}$ edition, Plenum Press-New York

[23] Reimer, L. (1998). Scanning Electron Microscopy, Physics of Image Formation and Microanalysis, $2^{\text {nd }}$ edition, SpringerVerlag

[24] McGonnagle, W.J. (1971). Nondestructive Testing, Gordon and Breach, Science Publ., New York, London, Paris

[25] Hellan, K. (1984). Introduction to Fracture Mechanics, McGraw-Hill, New York

[26] Polukhin, P., Gorelik, S., and Vorontsov, V. (1983). Physical principles of plastic Deformation, Mir Publishers, Moscow

[27] Hertzberg, R.W. (1989). Deformation and Fracture of engineering materials, Willey, 1989

[28] Shackelford, J.F. (2001). Introduction to Materials Science for Engineers, $5^{\text {th }}$ edition, Prentice Hall Inc

[29] Das, A.K. (1996). Metallurgy of Failure Analysis. Mc Graw-Hill

[30] Parton, V.Z. and Morozov, E.M. (1978). Elastic-Plastic Fracture Mechanics, Mir Publishers, Moscow (in English) 